\title{
Heightening Leader Development for Student Staff in College and University Recreational Sports Departments
}

\author{
By W. Zachary Weese ${ }^{*} \&$ W. James Weese
}

\begin{abstract}
University officials frequently trumpet their institution's record of developing leaders and many point to co-curricular programs (e.g., athletics, student government) as ideal settings for this type of development. Researchers have determined that interuniversity athletics programs are potentially fertile grounds for leadership development. The authors believe that recreational sport programs are undervalued and often underutilized units for the leader development in students. They suggest that collegiate recreation programs also offer vast opportunities for leadership development. High numbers of students occupy senior leadership positions with decision-making responsibilities, and they routinely engage in experiences that have the potential to develop and/or refine their leadership skills. However, this development could be enriched and enhanced. The authors chronicle the latest advancements in both leadership and leader development and offer Recreational Sport professionals 10 recommendations to heighten leadership development in their programs. Implementing these recommendations will facilitate richer learning and deeper development, and better align the programs with the trumpeted aspirations of their institution's senior leaders. The potential benefits to the student participants and the programs are also outlined in the paper.
\end{abstract}

Keywords: Student Leadership, Recreational Sports, Leadership Development.

\section{Introduction}

Recreational Sports Departments deliver outstanding programs that develop and/or refine the recreational skills and interests of the campus community and enrich the student experience (Forrester 2014). Some authors (Dugan et al. 2014, 2015, Hall 2013) have documented the merits of these programs and their undeniable role in student recruitment, retention, preparation, and enrichment. Campus officials also know the value of the campus recreational sport programs and facilities. They know that current and prospective students value these programs and facilities, and the contributions these programs make to student satisfaction and enrichment. Recreation and fitness facilities are usually "can't miss" stops on campus tours, and are prominently featured in electronic and print student recruitment materials. However, an area that doesn't get enough attention is the invaluable leadership development opportunities that students garner from assuming leadership roles in these programs (Dugan et al. 2015, Hall 2013).

\footnotetext{
*Manager of Governance and Special Projects, U SPORTS, Canada.

†Professor, Acting Vice-Provost, Associate Vice-President (International) \& Executive Director, Western Leader Academy, Western University, Canada.
} 
Student leaders in these programs often assume leadership roles that test their abilities, challenge their assumptions, and develop their skill sets. Students often assume decision-making roles that full-time professionals assume in other units across the respective campuses. The authors believe that these experiences help develop students and better prepare them for subsequent challenges they will face in work and life. However, the authors also believe that these developmental experiences could be enriched to facilitate greater learning and development, and they offer 10 theoretically-grounded recommendations (i.e., leadership and leader development areas) to facilitate greater growth. Recreational sport professionals would be well served by implementing these recommendations into a formal student staff leadership development program.

Recreational Sports professionals know that they could not offer their large programs without the support and assistance of student staff members (Hall 2015, Toperzer et al. 2011). These students provide the human resources needed to deliver a comprehensive university-based program (McFadden and Carr 2015). They frequently assume decision-making roles and are often afforded high levels of autonomy and authority to lead people and programs. Many get involved as first-year students, and with time and experience, gravitate to senior student leadership roles as they progress through their programs of study. Along the way, they have significant opportunities to develop their confidence, experience, and knowledge base, and deploy these attributes in senior leadership roles within the program. McFadden and Carr (2015) and Mumford et al. (2000) all highlighted the enriched leadership learning opportunities that these students can potentially accrue along the way. However, the authors believe that current and future Recreational Sports professionals could do more to heighten student leadership development. The latest advances in both leadership and leadership development make the recreational sport environment a perfect venue for student leader development (Parks 2005, Solansky 2010). In addition, an investment in heightening student leader development could heighten program effectiveness, enrich and advance the students' preparation, and better align the program with the stated mission of the educational institution.

Researchers (Day et al. 2014) confirm that leadership development programs must be meaningful to participants and adaptive to fit their developmental needs. In the recreational sport environment, the new students may need more technical content and experience, perhaps delivered, in part, by senior students. More developed, senior students would need advanced development, focused on conceptual and complex content. It is clear that the Recreational Sports environment is an ideal setting for student leadership development. The authors believe it could be enriched.

\section{Contemporary Leadership}

Our perspectives of leadership and how effective leaders operate have changed over time (Northouse 2015, Weese 2018). Contemporary leaders, and those in the future, will need to be team-oriented (Lencioni 2016, Petrie 2011). 
Their members will expect it, if not demand it. Rising technological advances and information overload will require leaders to make complex and timely decisions, sometimes with ambiguous information. Speed and accuracy will both be important. Members of groups or organizations will demand engagement. There will be days when leaders will be challenged with rising expectations, demand and accountabilities, in many of the same ways that student leaders feel when assuming more senior leadership roles at this critical time in their development. What a perfect opportunity for intervention and growth. Why not learn and advance leader development while enrolled as a student? Leader development researchers (Day et al. 2014, Parks 2005, Tingle et al. 2013) purport that leaders learn from experience, and purposeful deconstruction and reflection. They learn best when provided opportunities to lead, and from respected mentors who help them deconstruct and reflect upon their practices and outcomes.

Modern day leadership theorists have been focused on a team approach to leadership (Lencioni 2002, Welty Peachey et al. 2015). They purport the importance of leaders surrounding themselves with others who have complementary skills and applying these skills to help advance the ambitions of the organization. Weese (2010) encouraged Recreational Sports Directors to implement this practice in his: "The Four Steps to Exceptional Leadership of Campus Recreation in Turbulent Times" article. As he suggested, the team approach to leadership is especially well-suited to Recreational Sports given the size, scope and complex nature of the program. Contemporary leaders continue to operate in complex situations that call on leaders to manage information overload, integrate new technologies, and often deal with intergenerational issues (Petrie 2011). Today's leaders must be creative, adaptive, and strategic. They must be comfortable with people, and in fact, the more they advance in their career, the more they will draw on their emotional intelligence skills (Goleman 2013). A vast opportunity is provided to student leaders to develop these attributes employed in Recreational Sports Programs. We believe that these opportunities for leadership development could (Gould 2016, Parks 2005), and should, be further enriched.

The best leaders are conceptual thinkers. They know how things fit together and how the actions of one unit can impact another. This "conceptual skill" is developed with experience and enriched with practice and reflection. Student leaders in Recreational Sports are provided with countless opportunities to make decisions around complex issues. They can learn and grow from these experiences through purposeful coaching and by effectively reflecting on situations, decisions, and their outcomes. They can learn from the deconstruction and reflection of case studies of both common and complex scenarios that often emerge in the Recreational Sports area.

Another topic rapidly gaining attention in the leadership literature is the area of emotional intelligence. Writers like Goleman (2013), Goleman (et al. 2002) and Boyatzis and McKee (2005) defined an emotionally intelligent leader as a person who knows how to manage their emotions as well as those they lead. Emotionally-intelligent leaders inspire the hearts and minds of followers. The best leaders deploy abundant emotional intelligence in their leadership practices. 
These leaders are deeply concerned about the welfare, needs, and emotions of those they are charged with leading. Experts in the area believe that effective leaders have heightened levels of confidence, a deep commitment to those in their charge, and a heightened sensitivity to the emotional needs of followers. Weese $(2010,2018)$ and Nadler (2010) both considered emotional intelligence as being the critical ingredient of effective leadership. We have a great deal to learn from the rich literature base that is unfolding in the emotional intelligence and leadership area. Student leaders could be provided with workshops and seminars on pertinent leadership topics like, but limited to emotional intelligence, team building, participative governance, inclusion and leading in the $21^{\text {st }}$ century, and be afforded innumerable opportunities to practice and develop their areas in their day-to-day activities. Student leaders could also benefit from ongoing mentorship and coaching in these areas. Emotional intelligence is rapidly becoming the most important area in leadership (Goleman 2013) and student leaders will need to heighten their emotional intelligence skills as they progress through their careers. The same can be said for the team approach to leadership and participative governance (Lencioni 2016, Weese 2018). Recreational Sports professionals would be well served by ensuring that their members have access to resources (e.g., books, videos, articles) on these topics and other leadership to help them better understand the key components of effective leadership.

\section{Leadership Development Literature Review}

Leaders can be developed - and are in a variety of settings. Bennis and Thomas (2007) firmly concluded that leaders can be developed. Leadership scholars (Day et al. 2014, Parks 2005, Tingle et al. 2013) suggested that developing leaders need structured learning opportunities, experiences, mentoring, and reflection. Gardner (1995) suggested that leadership development programs must encourage developing leaders to understand that they need to present themselves as leaders. They must speak as a leader (Gardner 1995, Hall 2015). Bennis and Thomas (2007) concurred with this opinion by suggesting that leaders need a distinctive voice. They must act the part of the leader by being a strong communicator and transmitting their ideas in a clear, coherent, and cogent fashion. Effective leaders clearly articulate (and demonstrate) their values and communicate their expectations. Recreational Sport leaders can role model these attributes and work with senior student leaders to help them increase their confidence levels and develop these skill sets.

Leaders must be credible sources of information and also be perceived to be honest and trustworthy sources (Kouzes and Posner 1993). They also need to understand the importance of omnipresent honesty and trustworthiness. Emerging leaders also need to understand that they need to "get their ticket punched", and stay current so they are seen as credible sources of information. Unfortunately, there is abundant case study material that mentors can point to where strong, confident leaders lost their ability to influence others by cutting a corner, acting in a dishonest manner, not staying current, and consequently, 
losing the trust and respect of followers. Directors and other full-time staff members can, and must, serve as role models and reinforce these behaviors in coaching sessions with their student leaders. Senior student staff can fulfil the same role with the less experienced students that they lead.

Emerging and effective leaders have an insatiable appetite for growth and life-long learning. The best leaders are always open to new experiences and learning opportunities. Leaders in all levels of the program must adopt the mantra that they are a work in process. As Gardner (1995) noted, leadership is often learned from engaging leaders who effectively share stories and parables that have a leadership lesson. In his seminal book entitled Leading Minds: An Anatomy of Leadership, he noted that the best leaders are superb storytellers. He believed being exposed to great leaders was critical as long as followers reflected on the lessons learned. He suggests that aspiring leaders focus on their leader's words and actions and reflect on the achieved outcomes. The YMCA (Young Men's Christian Association) has adopted this practice by starting each staff and Board meeting with a "Y Story" that relays a "real-life" situation/occurrence at one of the YMCA locations. The story and the outcome become learning opportunities for their staff members and both help reinforce the YMCA's core values in addition to impacting a valuable leadership lesson. The key, of course, is the powerful, and underutilized process of reflection and its role in developing leaders (Day et al. 2014). Recreational sport leaders could close this loop with their student leaders in their coaching sessions.

Gardner (1995) also believed that leaders are developed by having their skills and judgement tested under pressure. In Recreational Sports programs, student leaders are continually challenged with stretch assignments that test their skill sets and experience. Positive results can help bolster their confidence levels and comfort in assuming more challenging tasks. However, effective leadership development does not occur through osmosis. These young leaders need to understand the theory underpinning the concept of leadership. They need to be afforded opportunities to practice leadership, and also receive ongoing coaching that often requires situation deconstruction and deep reflection of actions and resultant outcomes. These leaders could also benefit from effective role modeling and having senior leaders display effective leadership behaviors and then discuss situations with their young leaders during the reflection sessions. There should never be a "say-do" gap that is critical to establishing creditability in the eyes of followers and allowing leaders to effectively influence and develop their protégés.

Conger (1992) has long believed that leadership workshops (a.k.a. the spray and pray approach) will have limited long-term impact on leader development. Leadership development doesn't happen overnight or in response to a single leadership workshop (Day et al. 2014). Leadership scholars suggest that learning outcomes be established in advance of the development activities and the accompanying curriculum and activities be conceptually developed to meet the specific needs of participants. Having diagnostic data (e.g., Weese's 5C leader scores; Myer-Briggs Personality Type Assessment, etc.) in advance of program development might be helpful. Ongoing coaching and guidance 
should also be built into the program to ensure sustained and progressive development (Conger 1992).

Recreational Sports professionals have a wealth of leadership experience to share with student leaders and they can ensure that this content is reflected in the curriculum of programs. Conger is a proponent of having predetermined, mutually-agreed upon learning objectives in place at the start of any leader development program. He believes as well that a variety of learning strategies also need to be deployed to align with the leadership learning needs of participants, a position supported by Friedman (2008).

The second author on this paper has taught leadership at the graduate level for over 20 years. He does his best to ensure that his students understand the current thinking in leadership, apply the concepts to their lives and careers, and most of all, develop an insatiable passion for life-long learning in the field. Reflection is a large part of the strategy used in his class. Following the helpful advice of Spence et al. (2009) he implements intense deconstruction and deep reflection activities for case studies and vignettes that offer rich learning and development opportunities to heighten learning. He continually reaches out to alumni to see what they're doing and to attempt to measure any impact that the class has had on their leadership understandings and passion. The alumni also are engaged in his class and return to the class to share valuable insights on their experience, and how class content prepared them for leadership roles. In addition to helping prepare current students, the alumni are conduits for creating experiential opportunities, action research and networking opportunities for current students. This practice has direct application and high utility for the Recreational Sports domain (Nesbitt and Grant 2015). Former student leaders could be brought back to staff retreats and other structured leadership development sessions to help develop current student leaders.

Friedman $(2008,2014)$ offers a holistic approach to the area of leadership development that warrants adoption by Recreational Sports program officials. $\mathrm{He}$ encourages participants to try to connect leadership experiences from context of self, community, family leadership, and workplace perspectives. He believes that the most effective and satisfied leaders overlap their leadership contributions in these four roles. As Friedman (2008: 1) noted, total leadership interweaves two fields of study, namely "the study of leadership and the study of how individuals can find harmony among different parts of their lives". This is exceptional advice to impart to student leaders, and it should be incorporated into their formal leadership development program.

Consistent with modern thinking in leadership, Friedman begins his course with students identifying their core values. He then forces the students to think about these values and how they can be integrated into their career ambitions and current/future leadership practices. Students coach each other and they provide valuable feedback to the reflection exercises. Students are placed in triads and they meet on a regular basis to discuss issues, context, actions, and results. Students are continually reminded to review their values and be sure that they are being aligned to the leadership situations (i.e., from case studies or actual situations). Alumni stay engaged with the program to add perspective 
and richness to the discussion and extend the life-long engagement that Friedman believes is so critical to the process.

Recreational Sports leaders should adopt Friedman's $(2008,2014)$ approach, and ensure that students frequently reflect about how they can advance and integrate their self leadership, home leadership, community leadership, and workplace leadership practices. They should also ensure that the student leaders view leadership as a lifelong process (and commit to staying involved in the program upon graduation as an alumni mentor). Finally, student leaders need to trust one another so they can open up with respect to sharing their values, their decision processes, and their leadership practices. This will take time to develop, but Recreational Sports Directors could create rich learning opportunities and programs to build and reinforce this trust (e.g., by being seen to be trusting her/himself, common trust building activities and exercises.

Another technique that may have direct application to the Recreational Sports area is one developed at Harvard University (Heifetz et al. 1989). Heifetz and his colleagues teach leaders through traditional teaching methods (e.g., lectures, seminars, case studies), but they complement these methods with the concept he called "case-in-point" teaching. The case-in-point approach requires students to analyze situations that they encounter in small or large groups of other students. The aim of the process is to have students fully understand the context of the issue before discussing the best practice to resolve the situation. Students apply the knowledge and insights that they have gained from some of the traditional leadership development/class experiences. The Recreational Sports environment is filled with valuable case-in-point case studies that students and administrative staff could analyze and deconstruct prior to discussing potential solutions (McFadden and Carr 2015). This approach provides students with rich and relevant learning opportunities to apply leadership.

Regardless of the approach undertaken, it is fair to state that Campus Recreational Sports programs provide significant leadership development opportunities for students. Senior university leaders suggest that their institutions develop the "leaders of tomorrow". Recreational Sport programs have the potential to provide enriched settings for leader development that align perfectly with the advances in both the leadership and leader development research basis. With refinement, the authors believe that these programs could provide greater development. Ten suggestions have been developed that incorporate the latest thinking in leadership and leader development, and they are provided in the following section. Adopting some or all of these suggestions could significantly enrich student staff leader development which would undoubtedly lead to stronger student leadership in the program and greater program alignment with the overall mission of the institution. 


\section{Ten Suggestions for Heightening Student Leadership Development in Recreation Sports}

Leadership development should be an important component of a Recreational Sports program (Nesbitt and Grant 2015). If done right, Recreational Sports Directors will benefit from higher level day-to day contributions of better leaders making more prudent decisions and delivering higher levels of leadership. Once started, the tradition of leadership development will become embedded in the program. This could, and should lead to many program benefits. For example, the program could benefit from having higher developed student leaders engaged in its delivery. The leadership development program may also facilitate the student leader recruitment and retention efforts. High performing students may seek roles in the program, knowing that program leaders care about their development and demonstrate it by investing in their development. These student leaders may be more committed to the program because they know that their leaders care about them and their development (Goleman 2013). As well, the Recreational Sports Program Director and other colleagues in the Department will have additional talking points with campus leaders, greater alignment with the mission of the university, and create more opportunities for research and collaboration with campus colleagues doing research in the area of leadership and leader development. Finally, the Recreational Sports Directors can take solace in the fact that they've significantly helped develop and prepare the next generation of leaders.

The authors offer the following 10 suggestions for enhancing student leadership development in Recreational Sports. Some of these suggestions require zero to minimum financial resources to mount. Other suggestions may have cost implications for the program. The authors would argue that all ten of the suggestions are important and worthy investments given the purported benefits. However, Program Directors with resource challenges could choose to implement some of the suggestions and not of the more expensive options. The 10 suggestions are:

1. Create and resource a Leadership Development portfolio for the program and ensure that full time staff and student leaders at the Coordinator level and above commit to full engagement. Secure resources (e.g., books videos, newsletter, blogs) and make them available to colleagues. Develop an annual program of leadership development activities and share the schedule with your full-time staff members and student leaders so they can attend and participate in the slate of activities. These activities will reinforce your commitment to your members and their leadership development.

2. Start each academic year with a Leadership Retreat (on-site or if the budget allows, an off-site location). Deploy the suggestions of Lamson (2018) to maximize the efficacy and impact of the leadership development experience. The Director should ensure that a "lessons in leadership" module be offered. As Conger (1992) noted, a simple, clearly- 
delineated model of leadership will help students understand the key components of leadership. The use of pre-retreat readings and assignments will also prove to be beneficial (Lamson 2018). The group would also benefit from exposure to a wide variety of development exercises and activities to enrich and embed their learning (e.g., lectures, guest speakers, case studies, movie segments and discussion, reflection and personal assessment activities, physical activities like high ropes courses, and casein-point focus group sessions). Participants should also engage in selfleadership reflection activities (Friedman 2008, 2014, Petrie 2011) so they can better understand themselves, their values and their leadership tendencies. Petrie (2011) suggested that aspiring leaders need to understand their value system and leadership tendencies as a prerequisite to leading others. It may be valuable to incorporate diagnostic measures at this point (i.e., Myers-Briggs Personality Assessments, Weese's 5C Leadership Measures) so participants understand their values, leadership tendencies, blind spots, and areas in need of development. A thorough reflection activity should close the retreat along with a process to evaluate the event relative to leadership learning outcomes. Finally, an annual leadership development plan should be developed by each participant. The retreat should start with the Director delivering a talk on the history of the program and a statement on leadership development being a critical part of the program. The Director should communicate his/her commitment to leadership development. Engaging former student leaders who now hold leadership positions as speakers/mentors would also be prudent (Nesbitt and Grant 2015).

3. Ensure students are active in attending and presenting at student and professional conferences. Directors need to develop resources to support these activities. Some Directors may need to develop a Leadership Development Fund that student leaders can access through a "Call for Proposals" process. Student leaders should be required to file a Reflection Report upon their return to campus and make a presentation of the report and key leadership lessons gained through their participation in the Leadership Lunch (see Suggestion \#5).

4. Create a leadership mentoring program where senior student leaders mentor new students. The mentoring process is an effective approach to developing leaders and mentors, and it has a high degree of utility in both higher education and the recreational sports contexts (Dugan et al. 2014, Dugan et al. 2015). The mentor and the person being mentored need to sign an agreement outlining the pre-determined learning objectives, meeting schedules, and anticipated outcomes from the mentoring experience. The program could be further enriched by implementing the process outlined by Friedman (2008) and have former student staff members (alumni) be part of the group and engage the other two members electronically and in person. This would provide valuable senior level experience and practical insights to the process, as well as keep alumni and those who follow on a life-long path of 
learning. As Gardner (1995) astutely noted, leadership is a lifelong process. Regardless of who participates, it is critical that each participant will prepare a short report at the end of the year (used to plan the program for the next year) outlining the past year's activities, the realized outcomes relative to the pre-determined objectives, and any suggestions for improvement.

5. Hold a Leadership Lunch twice each term for participants in the Leadership Development Program. Bring in a campus leader or a colleague doing research in leadership to speak to student leaders on a current leadership topic (e.g., emotional intelligence; team approach to leadership; inclusion, diversity and leadership; vision and strategic thinking/action; organizational culture; character and leadership; gender and leadership, and; communications in the digital age). Hold sessions with students following these presentations to deconstruct the content and discuss opportunities to apply the content in a manner that improves operations as well as imbed deeper leader development.

6. Create complex situations for leaders to solve (e.g., host an annual conference), provide limited levels of coaching and monitor their activities, and then have members reflect and report on the leadership lessons learned through the experience(s).

7. Each term, stage a leadership workshop where student leaders are exposed to a program of leadership development. Occasional use of the "case-in-point" process would be well advised. Ensure that the groups of four to five students are assembled so they are balanced (e.g., age, area of responsibility). After each session have the small groups present their "case-in-point" scenario and resolution/integration of leadership learning to the entire group.

8. Engage your full-time leaders and your senior student leaders in a Leadership Book Club. Select a contemporary leadership book that you believe has relevance to the department. It may be helpful to ask members to provide book suggestions. Once selected, provide a copy of the book to each member of the senior leadership team and the senior student leaders. Assemble them into discussion groups of four to five members each, and ask them to come to the retreat prepared to address the following questions:

i. What are the key messages in the book?

ii. What are the most meaningful messages for you?

iii. How can the key concepts be incorporated into your leadership style?

iv. What can we do to ensure that our staff members understand and apply the key concepts outlined in the book?

v. How can we imbed the key concepts into our Department's culture? Your unit's culture?

9. Consider mentorship as a life-long process (Dugan et al. 2015). In the beginning, the relationship is often task-oriented with student leaders who generally lack experience and insights into the program, its 
philosophy, its culture, and its operations. In these early days, Directors often share insights, experience and institutional history with student leaders. As both the mentoring relationship and the skills sets of student leaders develop, the mentoring experience shifts to leaders and career life planning. They have the experience they need to make decisions, but the relationship building activities should continue. In fact, if done well, the mentoring experience continues for a lifetime, with former student leaders and Directors staying in touch, talking regularly, reflecting on past experiences, and focused on future career/life choices. For Directors, this is one of the most enriching components of a career in higher education. For student leaders, it is an enriching and valuable source of support and advice.

10. Leaders and their senior team need to model continual learning and development (Weese 2010, 2018). They must lead by example, ensuring their words and their actions align perfectly with the exposed values and stated leadership aspirations.

\section{Conclusion}

The leadership development literature base offers rich information that Recreational Sports Directors can access and implement to enrich the preparation and development of their student leaders and, by extension, the quality of their programs (McFadden and Stenta 2015). The Recreational Sports area is fertile ground for leadership development programs. If carried out effectively, the leadership development program can help prepare students to make greater contributions to the program, heighten their development and skill sets, and align the program with the central mission of the institution. Professionals interested in maximizing leadership development of their student leaders would be well served in implementing the 10 empirically-based suggestions noted in this manuscript. The program and the student leaders will be better for the experience.

\section{References}

Bennis WG, Thomas RJ (2007) Leading for a Lifetime. Boston, MA: Harvard Business School Publishing.

Boyatzis R, McKee A (2005) Resonant Leadership. Boston, MA: Harvard Business School Publishing.

Conger JA (1992) Learning to Lead: The Art of Transforming Managers into Leaders. San Francisco, CA: Jossey-Bass Publishers.

Day DV, Fleenor JW, Atwater LE, Sturm RE, McKee RA (2014) Advances in leader and leadership development: A review of 25 years of research and theory. The Leadership Quarterly 25(1): 63-82. 
Vol. 6, No. 3 Weese \& Weese: Heightening Leader Development for Student Staff in...

Dugan JP, Torrez MA, Turman NT (2014) Leadership in Intramural Sports and Club Sports: Examining Influences to Enhance Educational Impact. Corvallis, OR: NIRSA.

Dugan JP, Turman NT, Torrez MA (2015) When recreation is more than just sport: Advancing the leadership development of students in intramurals and club sports. Recreational Sports Journal 39(1): 37-48.

Forrester SA (2014) Benefits of Campus Recreation Sports Participation: Results from the NIRSA/NASPA Consortium Nationwide Survey of 33,522 Students. Corvallis, OR: NIRSA.

Friedman S (2008) Total Leadership: Be a Better Leader, Have a Richer Life. Boston, MA: Harvard Business School Publishing.

Friedman S (2014) Leading the Life You Want. Skills for Integrating Work and Life. Boston, MA: Harvard Business School Publishing.

Gardner H (1995) Leading Minds: An Anatomy of Leadership. New York: Basic Books.

Goleman D (2013) What Makes a Leader? Why Emotional Intelligence matters. Florence, MA: More than Sound LLC.

Goleman D, Boyatzis R, and McKee A (2002) Primal Leadership: Realizing the Power of Emotional Intelligence. Boston, MA: Harvard Business School Publishing.

Gould DR (2016) Leadership as a life skill in youth sports. In NL Holt (ed) Positive Youth Development Through Sport, 151-167. New York, NY: Routledge.

Hall SL (2013) Influence of campus recreation development on student learning. Recreational Sports Journal 37: 136-146.

Hall SL (2015) Linking the leadership identity model to collegiate recreation and athletics. In DA Stenta, CW McFadden (eds) Student Leadership Development Through Recreation and Athletics. Doi: 10.1002/yd.20141: 33-41.

Heifetz RA, Sinder RM, Jones A, Hodge LM, Rowley KA (1989) Teaching and assessing leadership courses at the John F. Kennedy School of Government. Journal of Policy Analysis and Management 8(3): 536-562.

Kouzes JM, Posner BZ (1993) Credibility: How Leaders Gain It and Lose It, Why People Demand It. San Francisco: Jossey-Bass.

Lamson M (2018) The Leadership Development Trends in 2018. Inc. Available at: https:/www.inc.com.melissa-lawson/top-learning-development-trends-for-2018.html.

Lencioni P (2002) The Five Dysfunctions of a Team. San Francisco, CA: Jossey-Bass.

Lencioni P (2016) The Ideal Team Player: How to Recognize and Cultivate the Three Essential Virtues. Hoeboken, NJ: Jossey-Bass.

McFadden CW, Carr JW (2015) Collegiate recreation student employee as student leader. In: DA Stenta, CW McFadden (eds) Student Leadership Development Through Recreation and Athletics. Doi: 10.1002/yd.20144: 65-76.

McFadden CW, Stenta DA (2015) Connecting collegiate recreation and athletics to leadership. In DA Stenta, CW McFadden (eds) Student Leadership Development Through Recreation and Athletics. Doi: 10.1002/yd.20138: 5-18.

Mumford M, Marks MA, Connelly MS, Marks MA, Zaccaro SJ (2000) The development of leadership skills: Experience and timing. The Leadership Quarterly 11(1): 87-114.

Nadler RS (2010) Leading with Emotional Intelligence: Hands-on Strategies for Building Confident and Collaborative Star Performers. New York: McGraw-Hill.

Nesbitt GM, Grant A (2015) Applying the multidimensional student of leadership findings to collegiate recreation and athletics. In DA Stenta, CW McFadden (eds) Student Leadership Development Through Recreation and Athletics. Doi:10.1002/y d.20139: 65-76.

Northouse PG (2015) Introduction to Leadership: Concepts and Practice. Thousand Oaks, CA: Sage. 
Parks SD (2005) Leadership Can Be Taught. Boston: Harvard Business School Publications.

Petrie N (2011) Future Trends in Leadership Development. Centre for Creative Leadership. Available at: https://bit.ly/2GskRbm.

Solansky ST (2010) The evaluation of two key leadership development program components: Leadership skills assessment and leadership mentoring. The Leadership Quarterly 21(4): 675-681.

Spence KK, Hess DG, McDonald, M., Sheehan BJ (2009) Designing experimental learning curricula for develop future sport leaders. Sport Management Education Journal 3(1): 1-25.

Tingle JK, Cooney C, Asbury SE, et al. (2013) Developing a student leadership program: The importance of evaluating effectiveness. Recreational Sports Journal 37: 2-13.

Toperzer L, Anderson DM, and Barcelona RJ (2011) Best practices in student development for campus recreation professionals. Recreational Sports Journal 35(2): $145-156$.

Weese WJ (2010) The four steps to exceptional leadership of Campus Recreation in turbulent times. Recreational Sports Journal 34(2): 95-102.

Weese WJ (2018) The 5C Leader: Exceptional Leadership Practices for Extraordinary Times. Bloomington, IN: Archway.

Welty Peachey J, Damon Z, Zhou Y, Burton LJ (2015) Forty years of leadership research in sport management; A review, synthesis, and conceptual framework. Journal of Sport Management, 29(5): 570-578. 
